\title{
UNDERSTANDING LESSONS OF ETHICS IN THE PRIMARY EDUCATION OF BANGLADESH
}

\author{
Alamgir Kabir ${ }^{1}$ Mehedi Imam $^{2}$. \\ Director, A K \& Associate, adakapn@gmail.com \\ ${ }^{2}$ Managing Director, Adhuna Bangladesh Ltd. m.imam@adhunabangladesh.com
}

\begin{abstract}
In a bid to understand the lesson of ethics in the existing primary education according to government approved syllabus in Bangladesh, a survey was carried out in Dhaka and Kushtia for students studying at class 1 to class $\mathrm{V}$, teachers and guardians. It has found that majority students are aware of 'right and wrong'. Their source of learning are parents as mostly found, followed by teachers and both. Majority of guardians think text books contain ethical knowledge and they are insufficient. All the teachers found the textbooks contain ethical knowledge and education but only one forth of them found those as insufficient. On appropriateness of the lessons, only a few teachers were satisfied but majority felt the need of ethical knowledge according to age and psychology. In the text books, moral lessons are found in religion, social and environmental context as a mere advice. They are available in the form of do's and don'ts. Stories carry ethical lesson but no individual lesson/chapter was found to be available in any books. The paper has tried to understand the existing syllabus in government run primary schools up to class $\mathrm{V}$ through interviewing students, teachers and guardians so that the level of lessons taught, and the need to learn the ethical knowledge can be assessed.
\end{abstract}

Key words: Lessons of Ethics, Primary Education and Bangladesh

Introduction: Primary level of education in Bangladesh is provided in various schools rather than a unified system in parallel with government approved/run syllabus. There are other syllabuses also to teach in primary level. Class V is the last step of primary education. Recently the national education policy has been drafted and introduces a new primary level of education where class VIII will be regarded as the last tier for entering into next level of education.

In this background, this is an effort to understand the existing ethical lesson in the syllabus in government run primary schools up to class $\mathrm{V}$ through interview students, teachers and guardians so that the level of lessons learnt in terms of acquiring ethical knowledge and the need for learning the lessons can be assumed. This is also can lead a wider research involving experts from various disciplines.

Objective: To study the lessons of ethics in the primary level of exiting education and their extent in the textbooks and teaching systems. 
Methodology: The study adopts a triangular methodology which includes a) reading of the books of the primary level b) interviewing of students, teachers and guardians, particularly parents and c) secondary data analysis through a number of sources such as web, papers and other printed materials.

The survey was conducted in June - July 2010 in two towns - Dhaka and Kushtia to catch up two different geographic locations.

It should be noted here that no personal information/socio-economic information was collected/recorded in terms of interviewees name, address, gender, age etc.

All statistical analyses were performed using the Statistical Package for Social Science (SPSS) $)^{3}$.

\section{Sample Number:}

A total of 93 persons were interviewed through a structured questionnaire and those include the following categories of respondents.

\begin{tabular}{|l|l|l|}
\hline Respondent & No & Percentage \\
\hline Teachers & 15 & 16.13 \\
\hline Students & 55 & 59.14 \\
\hline Guardians & 23 & 24.73 \\
\hline Total Number & 93 & 100 \\
\hline
\end{tabular}

Limitations of the study

Kindergarten and English medium school syllabus were not studied which is being taught in a large number of KG and English medium schools. Further, no interview was taken of trainers of the primary school teachers.

Findings: Findings of the questionnaire survey from three groups are summarised below separately followed by findings of the books of the primary level of education.

\section{Students}

- Out of 55 students, 43 students are aware of 'right and wrong'. It has also found that they can differentiate among these two.

- Their source of learning are parents as mostly found (27 students), followed by teachers (13 students), both (8 students).

- It is importantly noted that a few said about learning from relatives such as grand parents, other relatives in a close family.

- The highest response (36) on 'what lessons you have learnt' was received by 'Always speak the truth', followed by 'never tell a lie' (3). But 'read timely' was also received response from 5 students.

- Telling lie has been the most received response (37) as an unethical act, followed by disobeying parents (3), misbehaving with people (2).

- The study team was interested to inquire what sort of stories these students are fond of -28 students love to listen ghost story, followed by fantasy (22).

- Fairy tale received the 2 responses while stories with moral lessons were liked by 3 students.

${ }^{3}$ Version 11.0 
$-83.6 \%$ of students (46 students) feel guilty after doing a wrong and they all are ready to ask forgiveness.

\section{Guardians}

- $39 \%$ respondents as guardians ( 9 persons) think text books contain ethical knowledge and they are sufficient while $69.6 \%$ (16 persons) find the knowledge is appropriate.

- They have expressed they provide ethical knowledge to their children at home through advising them to speak truth, practical experience etc. This is also supported by their family members.

- All the guardians feel the necessity of learning and teaching ethical knowledge through providing more suitable knowledge on ethics with particular focus on making a habit by practice.

-21 guardians admits of social anarchy can be linked any way with the teaching of education and ethics as well.

\section{Teachers}

- All the 15 teachers found the textbooks contain ethical knowledge and education but only $26.7 \%$ (4 persons) found them as insufficient

- Those who do not find they are sufficient, feel the need of more lessons, constant care form family and relatives.

- On appropriateness of the lessons, only 6 teachers was satisfied but others feel the need of more knowledge according to age and psychology, practice both in the school and home.

- Most of the teachers (12 persons) received training on ethics and 13 teachers informed that they used to provide ethical knowledge outside the textbooks

- The need of ethics and spreading of its knowledge was felt by all the teachers and expressed that the knowledge should have to be spread in a better way, utilising up-to-date methodology

- The teachers mostly unwilling to make any link of social anarchy with the lack of ethical knowledge (12 teachers) and the three teachers find that knowledge, family and society can mould children mind.

\section{Books}

It has found from studying the text books that such lessons are found in religion, social environment as a mere advice. They are available in the form of do's and don'ts. in any books.

Stories carry lesson but no individual lesson/chapter was found to be available

Also, illustration is not that much attractive.

\section{Major Findings}

The summarized findings from all the sources provide the following points in general;

There is still a gap in understanding the ethical knowledge as mostly found with 'speak the truth'.

Moreover, the lessons are practice oriented, that is to say, they require practice and provided as moral. 

text books.

Understanding of the guardians and the teachers contradicted in some issues on

Most important, the study finds that family members care to the children is becoming less in learning/spreading ethical knowledge.

Discussion: Mahatma Gandhi once said: "Education means all-round drawing out of the best in child and man - body, mind and spirit." As such, education becomes the basis of personality development on all dimensions - moral, mental and emotional. Therefore, we all understand the need in the long run, education forms the foundations on which the castles of peace and prosperity can be built.

Since ancient times, it is said that with education we finally attain salvation. This essentially contains the thought and essence of value education that is relevant in all perspectives. This very concept, when applied to the simple but refined approach to the children, these is sure to provide us with a new dimension of educational development, benefit of which will be immense in the future to come. As such, while analyzing the views expressed by the respondents in three categories, we can observe them under two main points:

- $\quad$ Educate teachers, students and guardians (particularly parents) to inform them of their rights, their obligations, like the standards of service to be expected of teachers or the duty to send children to school, and of who to turn to in case of perceived wrongdoing.

- $\quad$ Since it is important to address issues relating to corruption and moral behaviour during the formative years, measures should be taken to address this, and to aim at creating a cultural sensitivity to all sort of unethical activities from an early age.

Conclusion: The survey found that ethical knowledge are mostly confined to understanding 'wrong and right', 'always speak the truth' etc. both for students and teacher's perspective. The guardians also fall in this understanding and ensure practices at home. But, it is understood that the level of ethical knowledge is a broad issue, practicing of which should be started at home with support from education materials and supported by the education institutions. Role of teachers in this regard is very important to understand those lessons and focus on the need.

Development and inclusion of proper knowledge of lessons and teaching materials is thus be sought by the teachers with comments from guardians so that an appropriate system can be introduced and run effectively for shaping the mind of the future leaders.

\section{References:}

1. All text books of Class I - V, National Textbook and Curriculum Board (eg., Bangla, English, Sociology, Religion, General Mathematics etc.)

\footnotetext{
${ }^{4}$ Gandhi On Value Education, by Dr. Ravindra Kumar (Dr. Ravindra Kumar is a universally renowned Gandhian scholar, Indologist and writer. He is the Former Vice-Chancellor of University of Meerut.)
} 
Bangladesh Bioethics Society 2010; 1(3):47-51

2. [Draft] National Education Policy 2010, GoB.

3.http://www.u4.no/helpdesk/helpdesk/queries/query25.c fm

4. 'Green signal to unified education system', The Daily Star, June 1, 2010. 